\title{
Immune Complexes from Immunized Mice and Infected Cystic Fibrosis Patients Mediate Murine and Human T Cell Killing of Hybridomas Producing Protective, Opsonic Antibody to Pseudomonas aeruginosa
}

Gerald B. Pier, Shugo Takeda, Martha Grout, and Richard B. Markham*

Channing Laboratory, Department of Medicine, Brigham and Women's Hospital, Harvard Medical School, Boston, Massachusetts 02115; and *Departments of Immunology and Infectious Diseases and Medicine, Johns Hopkins Medical Institutions,

Baltimore, Maryland 21205

\begin{abstract}
We examined the basis for the absence in cystic fibrosis (CF) patients of opsonic antibodies to the mucoid exopolysaccharide (MEP) antigen surrounding Pseudomonas aeruginosa that infect these patients. Opsonic antibodies to MEP are found in sera of the minority of $\mathbf{C F}$ patients that remain noncolonized into the second to fourth decades of life and protect rodents from chronic $P$. aeruginosa endobronchial infections. High titers of nonopsonic antibodies to MEP are found in $P$. aeruginosa-infected CF patients. Immunization of mice with doses of MEP that provoke only nonopsonic antibodies elicited $\mathrm{CD3}^{+}, \mathrm{CD8}^{+}, \mathrm{T}$ cell receptor $\alpha \beta$ receptor ${ }^{+}$, major histocompatibility complex-unrestricted cytotoxic lymphocytes specific for hybridoma cells producing opsonic but not nonopsonic antibodies. Cytotoxicity was dependent on immune complexes on the surface of the $T$ cells. Normal murine $T$ cells could be activated by concanavalin $A$ and sensitized with immune complexes for cytotoxic killing of hybridoma targets. CF patients infected with $P$. aeruginosa had serum immune complexes that sensitized concanavalin A-activated human $\mathbf{T}$ cells to kill murine hybridoma cells producing opsonic but not nonopsonic antibody. These results could explain the absence in infected CF patients of MEP-specific opsonins, an occurrence that accompanies the persistence of this infectious state. (J. Clin. Invest. 1993.91:1079-1087.) Key words: endobronchial infections $\bullet$ Fc receptors • immunosuppression • mucoid exopolysaccharide • phagocytosis.
\end{abstract}

\section{Introduction}

The appearance of chronic infections causing diseases such as AIDS, syphilis, and Lyme disease in previously immunocompetent individuals suggests that specific immune defects occur that interfere with the production of appropriate effectors to

This work was presented in part as an abstract at the 1990 meeting of the American Federation for Clinical Research and the 1992 Annual North American Cystic Fibrosis Conference.

Dr. Takeda's present address is Department of Pediatrics, Keio University School of Medicine, Tokyo, Japan.

Address reprint requests to Dr. Pier, Channing Laboratory, Harvard Medical School, 180 Longwood Avenue, Boston, MA 021155899.

Received for publication 27 March 1992 and in revised form 24 September 1992.

J. Clin. Invest.

(c) The American Society for Clinical Investigation, Inc.

0021-9738/93/03/1079/09 \$2.00

Volume 91, March 1993, 1079-1087 eliminate the pathogen. For example, the development of the chronic hepatitis B virus carrier state has been reported by Barnaba et al. (1) to be associated with the presence of HLA class I-restricted cytotoxic T lymphocytes (CTL) ${ }^{1}$ that kill B cells producing virus-specific neutralizing antibodies. Acquisition of persistent pulmonary infection with mucoid strains of Pseudomonas aeruginosa among cystic fibrosis (CF) patients remains the major complication leading to morbidity and death $(2,3)$. Persistence of the pathogen despite an intense immune response to bacterial antigens (4-8) suggests an immunologic defect specific to mucoid $P$. aeruginosa cells.

The outer bacterial coat of mucoid $P$. aeruginosa, termed mucoid exopolysaccharide (MEP) or alginate, is a major target for antibodies that mediate opsonic killing of the bacteria by leukocytes and complement $(9,10)$. However, antibodies that bind to MEP antigen but fail to mediate opsonic killing (nonopsonic antibodies) are frequently encountered among younger CF patients before the onset of infection (9) and are seen at elevated titers among chronically infected patients, who also fail to produce opsonic antibodies to MEP in response to infection (9). A small number $(<5 \%)$ of $C F$ patients escape this seemingly inevitable colonization by the second decade of life, and analysis of 16 of these patients showed that $88 \%$ had opsonic antibodies specific to MEP, indicating an association between the presence of opsonic antibodies and resistance to infection (9). Comparison of the protective efficacy of monoclonal and polyclonal opsonic antibodies with that of nonopsonic antibodies in rodent models of chronic $P$. aeruginosa infection showed protection only in the presence of opsonic MEP-specific antibodies (10). MEP-specific opsonic antibody differs from nonopsonic antibody by depositing high levels of the critical complement opsonins $\mathrm{C} 3 \mathrm{~b}$ and $\mathrm{C} 3 \mathrm{bi}$ on the outer bacterial surface, with most of these $\mathrm{C} 3$ fragments attached to the MEP (11). Thus, strategies to elicit MEP-specific opsonizing antibodies may eventually be applicable to the vaccination of CF patients against chronic $P$. aeruginosa infection.

The purpose of the present study was to identify specific immunologic mechanisms that may be responsible for the inability of CF patients to generate an MEP-specific opsonic antibody response during infection with $P$. aeruginosa. In mice, $1-10-\mu \mathrm{g}$ doses of MEP composed of moderate sized polymers ( mean coefficient of distribution $\left[K_{\mathrm{d}}\right]=0.26$ on a Sepharose CL4B column, approximate molecular size $400 \mathrm{kD}$ ) elicit opsonic antibody, whereas doses $\geq 50 \mu \mathrm{g}$ elicit only nonopsonic antibodies (12). These antibodies do not differ by isotype, but

1. Abbreviations used in this paper: $\mathrm{CF}$, cystic fibrosis; CTL, cytotoxic T lymphocyte(s); MEP, mucoid exopolysaccharide; TCR, T cell receptor(s). 
are directed at different epitopes on the MEP antigen $(9,11)$ and differ in their ability to deposit covalently linked C3 fragments onto the bacterial surface (11). After an initial 50- $\mu \mathrm{g}$ dose, a booster dose of $1 \mu \mathrm{g}$ fails to elicit opsonic antibodies in these mice, and this inability to produce opsonic antibodies could be adoptively transferred to nonimmune mice by splenic $T$ cells (12). In light of recent reports by various investigators $(1,13,14)$ that $\mathrm{T}$ cells can kill $\mathrm{B}$ cells, we investigated whether $T$ cells elicited in response to immunization with high doses of MEP could kill hybridoma cells producing MEP-specific opsonic and nonopsonic antibody.

\section{Methods}

Bacterial strains and antigens. Mucoid P. aeruginosa strain 2192, originally obtained from the sputum of a CF patient, was used to isolate MEP antigen as described (12). The MEP used to immunize mice for studies of cytotoxic T cell activity had a $K_{\mathrm{d}}<0.3$ (approximate molecular size $<300 \mathrm{kD}$ ) and provoked only nonopsonic antibodies to MEP when given at doses of $50 \mu \mathrm{g}$ per mouse. High molecular weight polysaccharide from $P$. aeruginosa was also prepared as described (15).

Hybridoma cells. Hybridoma cells secreting MEP-specific opsonic and nonopsonic antibodies were obtained by standard methods after immunization of BALB/c mice with purified antigens or whole bacterial cells. The resulting monoclonal antibodies were classified as opsonic or nonopsonic using an opsonophagocytosis assay employing these antibodies along with either human peripheral blood leukocytes or murine inflammatory peritoneal cells, complement, and mucoid $P$. aeruginosa strain 2192 as described (16). In this study hybridomas $8 / 5) 31$ and $9 / 5) 23$ both secreted $\operatorname{IgG}_{2 b}$ opsonic antibodies to MEP, while hybridoma $\mathrm{M} / \mathrm{K}$ ) 16-E2 secreted a nonopsonic $\mathrm{IgG}_{2 \mathrm{~b}}$ antibody and hybridoma $\mathrm{M}) \mathrm{K} / 32-\mathrm{C} 3$ secreted an IgM nonopsonic antibody. Hybridoma 3D9 secretes an $\mathrm{IgG}_{3}$ monoclonal antibody specific to a group B streptococcal antigen and was kindly supplied by $\mathrm{L}$. Madoff of the Channing Laboratory. Myeloma P3X was obtained from the American Type Culture Collection, Rockville, MD.

Cytotoxicity assays. For cytotoxicity assays, $2 \times 10^{6}$ target hybridoma cells were labeled for $14 \mathrm{~h}$ with $100-300 \mu \mathrm{Ci}$ of ${ }^{51} \mathrm{Cr}$ and washed repeatedly; $2 \times 10^{4}$ target cells were then added to cultures of $\mathrm{T}$ cells obtained as described below from the spleens of BALB/c $\left(\mathrm{H}-2^{\mathrm{d}}\right)$ mice immunized 6-8 d previously with $50 \mu \mathrm{g}$ of moderate sized MEP (12). $\mathrm{T}$ cells were cultured along with ${ }^{51} \mathrm{Cr}$-labeled target cells at $37^{\circ} \mathrm{C}$ in $5 \%$ $\mathrm{CO}_{2}$. Maximal release of ${ }^{51} \mathrm{Cr}$ occurred by $6 \mathrm{~h}$ and remained stable for up to $18 \mathrm{~h}$. Therefore, all assays were run for $16-18 \mathrm{~h}$. The cells were pelleted by centrifugation of the tissue culture plate and a measured aliquot of the supernate removed and counted in a gamma counter. Percent release of ${ }^{51} \mathrm{Cr}$ was calculated by subtracting out the mean of the nonspecific cpm of ${ }^{51} \mathrm{Cr}$ released from target cells in the absence of $T$ cells from the mean of the experimental values and dividing this figure by the mean of the cpm of ${ }^{51} \mathrm{Cr}$ in the target cells at the beginning of the assay minus the mean of the nonspecific cpm of ${ }^{51} \mathrm{Cr}$ released. In assays where additional factors such as MEP antigen were added to test wells containing $\mathrm{T}$ - and hybridoma cells, the nonspecific release of radioactivity was measured in wells containing labeled hybridoma cells and the measured amount of additional factors.

Isolation of T cells. T cells were isolated from spleens of mice immunized intraperitoneally with the indicated dose of antigen in $0.2 \mathrm{ml}$ of saline. Mice were killed by cervical dislocation; their spleens were removed, minced into single-cell suspensions, and washed; red cells were lysed by treatment for $10 \mathrm{~min}$ at $37^{\circ} \mathrm{C}$ with $1 \%$ ammonium chloride; adherent cells removed by incubation on plastic petri plates for $45 \mathrm{~min}$ at $37^{\circ} \mathrm{C}$, and $\mathrm{B}$ cells were removed by double panning on petri plates coated with anti-mouse IgM, as described by Wysocki and Sato (17). The concentration of $T$ cells was adjusted after manual counting in a hemocytometer. Testing of the efficacy of this procedure by fluorescent-activated cell-sorting analysis for CD3 and IgM antigens indicated that $>95 \%$ of the cells routinely obtained were $\mathrm{T}$ cells. Activation of $\mathrm{T}$ cells by concanavalin A (Con A) was accomplished by incubating $10^{6}$ cells/ml of RPMI 1640 medium containing $10 \%$ fetal bovine serum and $2.5 \mu \mathrm{g} \mathrm{Con} \mathrm{A} / \mathrm{ml}$. After $48 \mathrm{~h}$ at $37^{\circ} \mathrm{C}$ in $5 \% \mathrm{CO}_{2}$ cells were washed twice in RPMI 1640 medium, counted manually in a hemocytometer, and adjusted to the desired concentration for use in the cytotoxicity assay.

Depletion of $T$ cells bearing specific surface antigens. Polyclonal antibodies to the Thy 1, CD3, CD4, and CD8 antigens, along with rabbit Lo-Tox complement, were obtained from Accurate Chemical and Scientific Corp., Westbury, NY, and generally were used at a 1:10 dilution. Monoclonal antibodies to murine $\alpha \beta$ T cell receptor (TCR) (clone H57-957, Hamster IgG) and $\gamma \delta$ TCR (clone GL3, Hamster IgG) and $\mathrm{FcR} \gamma$ (clone 2.4G2, Rat $\operatorname{IgG}_{2 \mathrm{~b}}$ ) were obtained from PharMingen, San Diego, CA. T cells were incubated with the antibodies or normal mouse serum as a control at $4^{\circ} \mathrm{C}$ for $45-60 \mathrm{~min}$, washed once in RPMI medium, resuspended in $10 \%$ rabbit Lo-tox complement, and incubated at $37^{\circ} \mathrm{C}$ for $30 \mathrm{~min}$. Cells were washed twice and resuspended in the original volume, then added to cytotoxicity assays. Independent measurements of the $50 \%$ hemolytic level of complement $\left(\mathrm{CH}_{50}\right)$ after incubation of the monoclonal antibodies with isolated $\mathrm{T}$ cells and complement indicated a minimum decrease of $50 \%$ in $\mathrm{CH}_{50}$, showing these antibodies do fix rabbit complement.

Cytotoxicity assays employing human sera and cells. Sera from CF patients were used from our collection of samples obtained from patients attending the outpatient clinic at Children's Hospital, Boston. All samples were obtained after informed consent was given by either the patient or their parent. Peripheral blood was obtained from non CF volunteers giving informed consent, and mononuclear cells were recovered by separation on Mono-Poly resolving medium (ICN Biomedical, Costa Mesa, CA ). Cultures of $10^{6}$ lymphocytes $/ \mathrm{ml}$ were established in RPMI medium supplemented with $10 \%$ fetal calf serum and $2.5 \mu \mathrm{g} / \mathrm{ml}$ Con A. Cultures were incubated for $48 \mathrm{~h}$ in $5 \% \mathrm{CO}_{2}$ at $37^{\circ} \mathrm{C}$. Viable cells were recovered by washing, manually counted in a hemocytometer after staining with trypan blue, and resuspended to $5 \times 10^{6}$ in RPMI medium with $10 \%$ fetal calf serum. A $100-\mu \mathrm{l}$ volume of human T cells activated by $\mathrm{Con} A$ was mixed with $2 \times 10^{4} \mathrm{S1} \mathrm{Cr}$-labeled target murine hybridoma or myeloma cells and $1 \%$ (final concentration) test human serum in the presence or absence of $5 \mu \mathrm{g}$ MEP antigen per well. Cultures were incubated overnight at $37^{\circ} \mathrm{C}$ in $5 \% \mathrm{CO}_{2}$, and the released ${ }^{51} \mathrm{Cr}$ was measured in a gamma counter after removal of cells by centrifugation.

Statistical analysis. Statistical analyses of the data were performed on a Macintosh II computer using the Statview software package.

\section{Results}

Cytotoxic killing of target hybridoma cells. Fig. $1 A$ shows that $T$ cells obtained from the spleens of BALB/c mice immunized $6 \mathrm{~d}$ previously with $50 \mu \mathrm{g}$ of MEP antigen killed a high proportion of two different hybridomas [8/5)31 and 9/5)23] producing $\mathrm{IgG}_{2 \mathrm{~b}}$ opsonizing antibodies to MEP. The rate of killing was comparable to that observed for a positive control of cytotoxic $T$ cells obtained from $B A L B / c$ mice immunized directly with $10^{7}$ of the target hybridoma cells. T cells from BALB/c mice immunized with $50 \mu \mathrm{g}$ of an irrelevant polysaccharide only marginally killed the target hybridoma cells, as did $\mathrm{T}$ cells from BALB/c mice given a 1- $\mu$ g dose of MEP, which elicits opsonic antibody. Fig. $1 B$ shows that $\mathrm{T}$ cells from BALB/c mice immunized with $50 \mu \mathrm{g}$ of MEP specifically lysed the two hybridomas producing opsonic antibodies; significantly $(P$ $<0.01$ ) less ${ }^{51} \mathrm{Cr}$ release was evident for two distinct hybridomas producing nonopsonic antibodies $[\mathrm{M}) \mathrm{K} / 32-\mathrm{C} 3$ and $\mathrm{M}) \mathrm{K}$ /16-E2), or another hybridoma cell line producing an irrelevant monoclonal antibody (3D9) or the myeloma fusion 
A
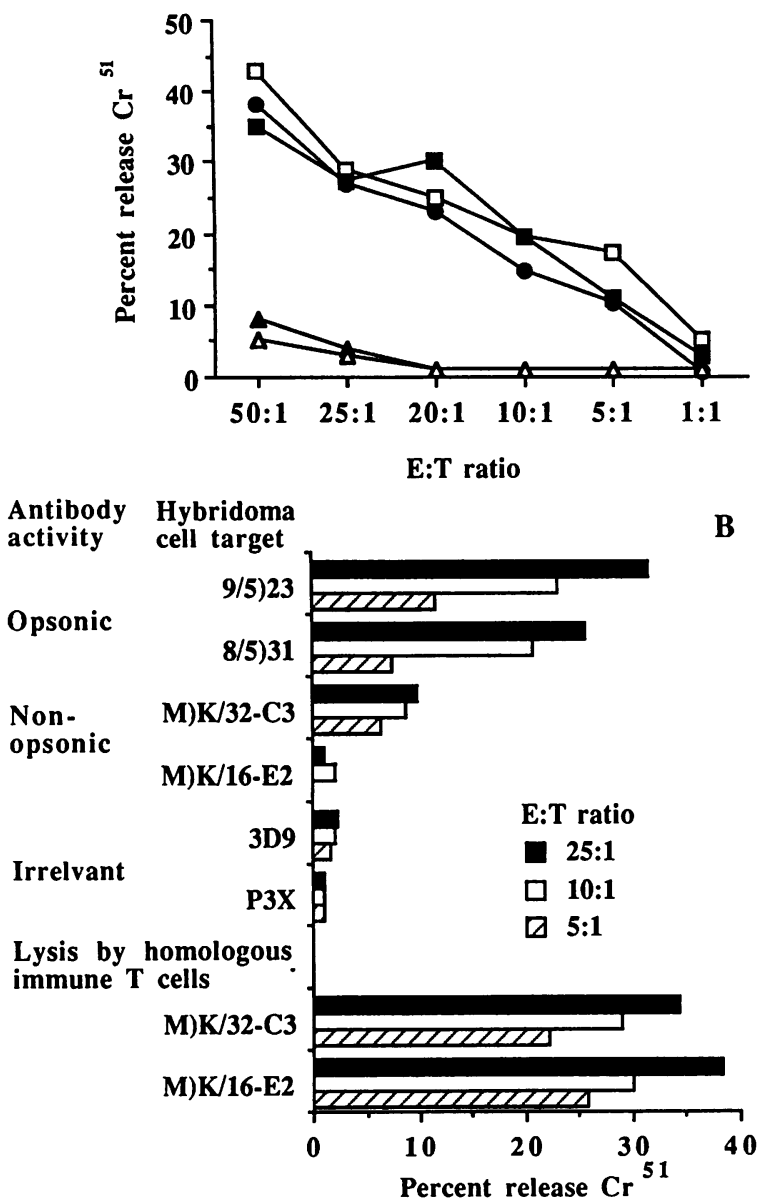

Figure 1. Killing of B cell hybridomas by T cells. $(A)$ Release of ${ }^{51} \mathrm{Cr}$ from hybridomas 8/5)31 (口) and 9/5)23( $\bullet$ ), which secrete MEP-specific opsonic monoclonal antibodies $\left(\operatorname{IgG}_{2 b}\right)$, incubated at the indicated ratio of effector $T$ cells to target $B$ cells ( $E: T$ ratio); in this case $T$ cells were obtained from BALB/c mice immunized with $50 \mu \mathrm{g}$ of MEP antigen. Also shown is the release of ${ }^{51} \mathrm{Cr}$ from hybridoma 8/5)31 incubated with T cells from BALB/c mice immunized with: $1 \mu \mathrm{g}$ of MEP antigen $\left.(\Delta) ; 10^{7} 8 / 5\right) 31$ hybridoma cells $(\bullet) ; 50$ $\mu \mathrm{g}$ of heterologous high molecular weight polysaccharide from the immunotype 1 strain of $P$. aeruginosa $(\Delta)$. Points represent the mean of duplicate determinations and are representative of experiments performed at least three times. $(B)$ Release of ${ }^{51} \mathrm{Cr}$ mediated by $\mathrm{T}$ cells from BALB/c mice immunized with $50 \mu \mathrm{g}$ of MEP antigen from the same hybridomas in $A$ secreting opsonic antibodies; from hybridoma targets secreting MEP-specific nonopsonic antibodies, $\mathrm{M}$ ) K/32-C3 and $M$ )K/16-E2, (IgM and $\operatorname{IgG}_{2 b}$, respectively); from hybridoma 3D9 (which secretes an irrelevant $\mathrm{IgG}_{3}$ antibody to a group B streptococcal protein antigen); and from myeloma cell line P3X. The bottom of the graph shows that hybridomas $\mathrm{M}) \mathrm{K} / 32-\mathrm{C} 3$ and $\mathrm{M}$ ) $\mathrm{K}$ / 16-E2 can be lysed, as measured by ${ }^{51} \mathrm{Cr}$ release, when specific immune $T$ cells from BALB/c mice are added (obtained from BALB/c mice immunized with $10^{7}$.of the hybridoma cells in adjuvant). Target cells were incubated for $16 \mathrm{~h}$ at the E:T ratio indicated. Bars represent the mean of duplicate or triplicate determinations.

partner P3X. To insure that the hybridomas producing nonopsonic antibodies were susceptible to $\mathrm{T}$ cell lysis, splenic $\mathrm{T}$ cells from BALB/c mice immunized 6 days previously with $10^{7}$ hybridoma cells in complete Freund's adjuvant were tested for their ability to lyse homologous and heterologous hybridoma targets. Both hybridomas secreting nonopsonic antibodies elic- ited cytotoxic $\mathrm{T}$ cells that efficiently lysed their homologous targets (Fig. $1 B$ ); the cytotoxic T cells only poorly lysed $(<8 \%$ ${ }^{51} \mathrm{Cr}$ released, not shown) heterologous targets, indicating only minimal activation of cytotoxic activity by including adjuvant in the immunizing mix.

Studies using $\mathrm{T}$ cells from allogeneic mice $(\mathrm{C} 57 \mathrm{Bl} / 6$, [H$\left.2^{b}\right]$, and $\left.\mathrm{C} 3 \mathrm{H} / \mathrm{HeN},\left[\mathrm{H}-2^{\mathrm{k}}\right]\right)$ immunized with $50 \mu \mathrm{g}$ of MEP showed these cells also could kill the target hybridomas producing opsonic antibodies and did not kill hybridomas producing nonopsonic antibody, indicating a lack of major histocompatibility complex (MHC) restriction in this phenomenon (not shown).

Phenotypic markers on cytotoxic $T$ cells. The phenotypic characteristics of the $T$ cells mediating the killing of the hybridomas are shown in Fig. 2. Depletion of splenic $T$ cells with antibody specific to the indicated cell surface marker and complement revealed that the majority of the effector CTL were depleted by treatment with antibody to CD3, CD8 (lyt 2.2) and the $\alpha \beta$ TCR but not the CD4 (L3T4) or $\gamma \delta$ TCR. Nu/nu $\mathrm{BALB} / \mathrm{c}$ mice immunized with $50 \mu \mathrm{g}$ of MEP did not have splenic cells that could kill the hybridomas (not shown).

Cytotoxic $T$ cells interact with target hybridoma cells via surface immune complexes. Since cytotoxicity was MHC unrestricted but specific to hybridoma cells secreting antibody binding to one epitope on a multivalent antigen $(9,11,16,18)$ this suggested that cytotoxic $\mathrm{T}$ cells may recognize target cells via immune complexes bound to Fc receptors, with the bound antigen serving as a bridge to the immunoglobulin receptors on the surface of the target cells. In this case, hybridomas secreting either opsonic or nonopsonic antibodies to MEP should bind to the cytotoxic $\mathrm{T}$ cells and inhibit their lysis of hybridomas producing opsonic antibody. Thus, to investigate the mechanism whereby cytotoxic $T$ cells recognize the target hybridoma cells, we used cold target inhibition assays employing hybridomas secreting either opsonic or nonopsonic antibodies, both

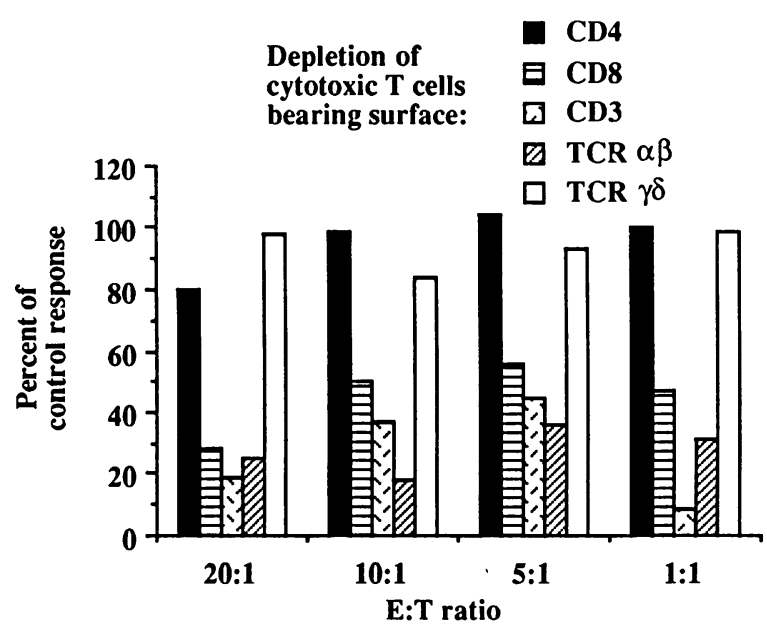

Figure 2. Characterization of cell surface antigens expressed by cytotoxic $T$ cells. Isolated $T$ cells were obtained from mice immunized $6 \mathrm{~d}$ previously with $50 \mu \mathrm{g}$ of MEP antigen. T cells bearing the cell surface markers indicated in the legend were depleted as described in experimental procedures. They were then mixed at the indicated $\mathrm{E}: \mathrm{T}$ ratio for $18 \mathrm{~h}$ and the rate of response was determined using nondepleted $\mathrm{T}$ cells as a control. Bars represent the mean of triplicate determinations. The net percentage of ${ }^{51} \mathrm{Cr}$ released by $\mathrm{T}$ cells treated with normal mouse serum was E:T ratio 20:1, 48\%; 10:1, 34\%; 5:1, $23 \% ; 1: 1,12 \%$. 
of which bind MEP antigen via distinct epitopes (11). Both types of unlabelled hybridoma cells inhibited, in a dose-dependent fashion, the killing of target hybridomas that produced opsonic antibodies; in contrast a hybridoma secreting irrelevant antibody failed to inhibit killing (Fig. 3).

We next added varying amounts of MEP to cytotoxicity assays to determine further if immune complexes are involved in $\mathrm{T}$ cell recognition of target hybridoma cells. Addition of MEP antigen up to $70 \mu \mathrm{g} / \mathrm{ml}$ enhanced target cell lysis in a dose-dependent fashion (Fig. 4). Enhancement of lysis was specific to hybridomas producing opsonic antibodies and addition of MEP antigen did not promote the otherwise low-level release of ${ }^{51} \mathrm{Cr}$ from hybridomas producing nonopsonic antibodies (Fig. 4).

The above data implicate FcR-positive $T$ cells armed with immune complexes composed of MEP-specific antibody and MEP antigen as the mediators of the observed cytotoxicity. Presumably the antigen component is derived from the immunizing material, but the antigen enhancement of cytotoxicity shown in Fig. 4 suggests that there are FcR bound MEP-specific antibodies available to bind additional antigen, resulting in increased cytotoxicity. In addition, the membrane bound antibody on the B cells must be available to bind epitopes on this multivalent polysaccharide antigen, indicating that the mechanism of target cell recognition is via formation of a bridge between the $\mathrm{T}$ cell and target cell. This bridge would consist of FcR bound antibody on the $T$ cell and antigen binding both this antibody and membrane bound antibody on the target hybridoma cell. If this model were correct, one would expect that addition of free antigen to isolated $T$ cells would result in increased saturation of the FcR bound specific antibody on these cells, thereby providing a greater opportunity for the interaction between $T$ cells and target hybridoma cells.

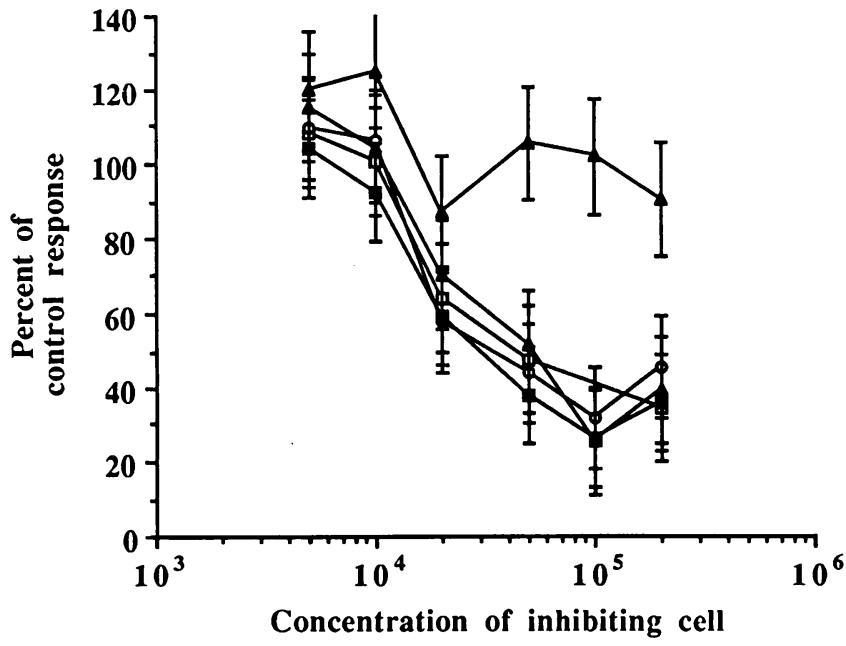

Figure 3. Inhibition of cytotoxic $\mathrm{T}$ cell activity by unlabeled hybridoma cells. Inhibition assays employed labeled 8/5)31 hybridoma targets and T cells from mice immunized $6 \mathrm{~d}$ previously with $50 \mu \mathrm{g}$ of MEP antigen at an E:T ratio of 25:1. Unlabeled inhibiting hybridoma cells were added at the indicated concentration to the assay. Unlabeled inhibiting hybridomas were 8/5)31 (ם) and 9/5)23( $\Delta$ ), which secrete opsonic antibodies to MEP; M/K)16-E2 (O) and M/ K) 32-C3 ( $\bullet$ ), which secrete nonopsonic antibodies to MEP; and the irrelevant hybridoma target 3D9 ( $\Delta$ ). Points indicate the mean of triplicate determinations and error bars the standard error. The net percent release of ${ }^{51} \mathrm{Cr}$ from uninhibited cells was $52 \%$.

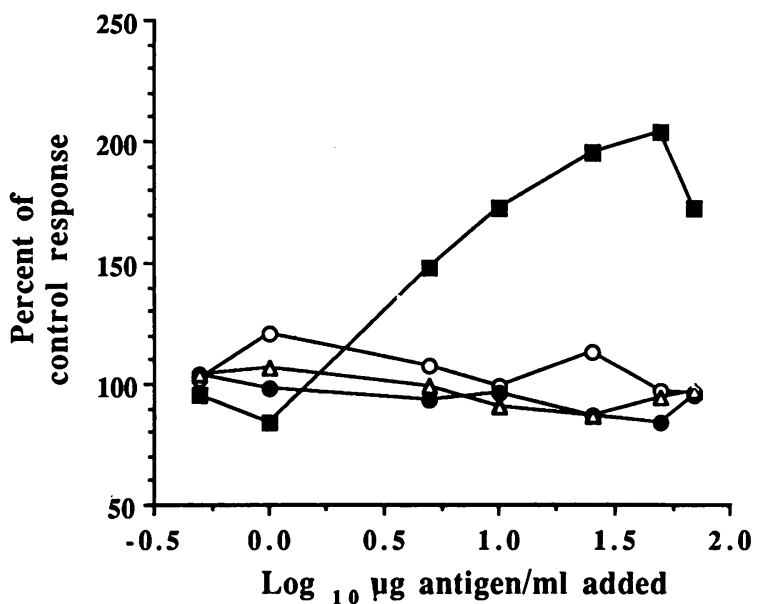

Figure 4. Effect of added antigen of cytotoxicity. Either MEP antigen $(\bullet)$ or an irrelevant polysaccharide $(\bullet)$ were added to cytotoxicity assays employing ${ }^{51} \mathrm{Cr}$ labeled 8/5)31 cells as targets and T cells obtained from mice immunized $6 \mathrm{~d}$ previously with $50 \mu \mathrm{g}$ of MEP as cytotoxic effectors at an E:T ratio of 25:1. The specificity of enhancement of hybridoma cell lysis in the presence of added MEP antigen is shown by the inability of added MEP to enhance lysis of two hybridomas secreting nonopsonic antibody to MEP: M)K/16-E2 (O) and $M / K) 32-C 3(\Delta)$. The indicated dose of MEP antigen was added to the cytotoxicity assay and the release of ${ }^{51} \mathrm{Cr}$ determined after 18 h. Nonspecific release of radioactivity for background subtractions was determined in cultures containing labeled hybridoma cells and MEP antigens at the different concentrations tested. Addition of MEP antigen to labeled hybridoma cells in the absence of $\mathrm{T}$ cells did not result in $>4 \%$ increase in the release of ${ }^{51} \mathrm{Cr}$ compared with labeled cells lacking additional antigen. Points indicate the mean of triplicate determinations. The net percent release of ${ }^{51} \mathrm{Cr}$ from labeled hybridomas in the absence of added antigen was $42 \%$.

When we added increasing amounts of MEP antigen to T cells before their addition to labelled targets, increased lyses of the targets was observed (Fig. $5 A$ ). Addition of an irrelevant polysaccharide antigen failed to increase target cell lysis.

This model would also predict that once the antibody on the surface of the $T$ cell was saturated with antigen, the addition of further antigen to the assay should begin to interfere with the binding of the $\mathrm{T}$ cell to hybridoma targets by saturating antigen binding sites on the hybridoma targets. This would result in decreased target cell lysis. When $T$ cells previously incubated for $1 \mathrm{~h}$ with $100 \mu \mathrm{g} / \mathrm{ml}$ of MEP antigen to saturate surface antibody (Fig. $5 \mathrm{~A}$ ) were added to target hybridoma cells in the presence of increasing amounts of MEP antigen, a dose-dependent inhibition of lysis was observed (Fig. $5 B$ ). An irrelevant polysaccharide antigen had no such effect. These data support the concept that in this system cytotoxic T cell activity is dependent upon MEP antigen serving as a bridge between FcR bound antibody on the cytotoxic $T$ cells and membrane antibody on the target hybridoma cells.

To determine further if immune complexes on the surface of the $\mathrm{T}$ cell were involved in recognition of target hybridoma cells, we immunized mice with $50 \mu \mathrm{g}$ of MEP and $6 \mathrm{~d}$ later exposed isolated splenic T cells to pH 5.0 for 5-15 min, a procedure previously employed to dissociate $\mathrm{T}$ cell bound antibody from antibacterial $T$ cells $(19,20)$. Under these conditions, cytotoxic activity was restored only if both MEP-specific antibody and MEP antigen were added back to the assay (Fig. 6 $A$ ). The antibodies could be specific for epitopes that bind ei- 
$\mathbf{A}$

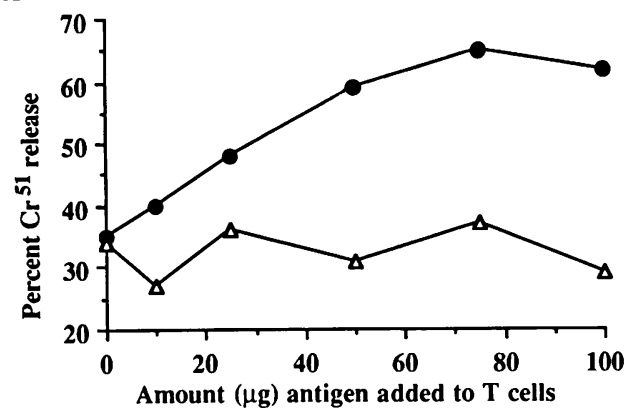

B

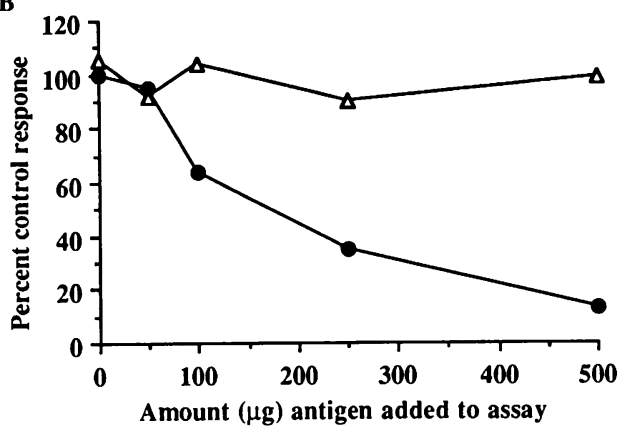

Figure 5. $(A)$ Cytotoxic activity against labeled 8)5/31 hybridoma cells of T cells from mice immunized with $50 \mu \mathrm{g}$ of MEP after incubation for $1 \mathrm{~h}$ at $37^{\circ} \mathrm{C}$ with the indicated concentration of additional $\operatorname{MEP}(\bullet)$ or an irrelevant polysaccharide $(P S)$ antigen $(\triangle)$ (high molecular weight polysaccharide from Fisher IT-1 P. aeruginosa). (B) Immune T cells were first incubated with $100 \mu \mathrm{g} / \mathrm{ml}$ of MEP, washed, and added to cultures of radiolabeled 8)5/31 hybridoma cells containing the indicated dose of $\operatorname{MEP}(\bullet)$ or the irrelevant PS $(\Delta)$ from IT-1 P. aeruginosa. Points indicate mean of triplicate determinations. The net percent release of ${ }^{51} \mathrm{Cr}$ from labeled hybridomas in the absence of added antigen was $61 \%$.

ther opsonic or nonopsonic antibody, inasmuch as $\mathrm{IgG}_{2 \mathrm{~b}}$ monoclonal antibodies expressing either biologic activity could restore cytotoxic activity to $\mathrm{pH} 5.0$-exposed immune $\mathrm{T}$ cells in the presence of MEP antigen (Fig. $6 \mathrm{~B}$ ). In addition, immune $\mathrm{T}$ cells exposed to $\mathrm{pH} 5$ in order to dissociate surface immune complexes from $\mathrm{Fc}$ receptors and then reconstituted with MEP-specific antibody could be removed from cell suspensions by incubation on petri plates coated with MEP, but not incubation on petri plates coated with an irrelevant polysaccharide antigen from $P$. aeruginosa (not shown). Hybridomas producing nonopsonic antibody were not susceptible to lysis after acid treatment (not shown).

Activated normal splenic $T$ cells can bind immune complexes and lyse target hybridoma cells. Another set of experiments was performed to verify that recognition of the target hybridoma was due to surface immune complexes. As shown above (Fig. 1) T cells from nonimmune animals failed to kill target hybridoma cells, and also failed to kill these cells when specific antigen and antibody were added to the assay (not shown). We therefore incubated T cells from normal BALB/c mice for $48 \mathrm{~h}$ in the presence of $2.5 \mu \mathrm{g} / \mathrm{ml}$ of Con A, a mitogen known to activate $\mathrm{CD} 8{ }^{+} \mathrm{CTL}(21)$. These activated T cells were then incubated in the cytotoxicity assay along with various combinations of MEP-specific antibody and/or MEP antigen or with nonimmune serum and MEP antigen; hybridoma cells secreting opsonic antibody to MEP served as targets. The Con A-activated T cells killed the hybridoma cells only when MEP-specific antibody and antigen were present (Fig. 7 $A$ ). Con A-activated $\mathrm{T}$ cells did not kill the same heterologous targets shown in Fig. $1 B$ in the presence of MEP-specific antibody and antigen (not shown), nor was cytotoxic activity evident if cells were not exposed to Con A (not shown).

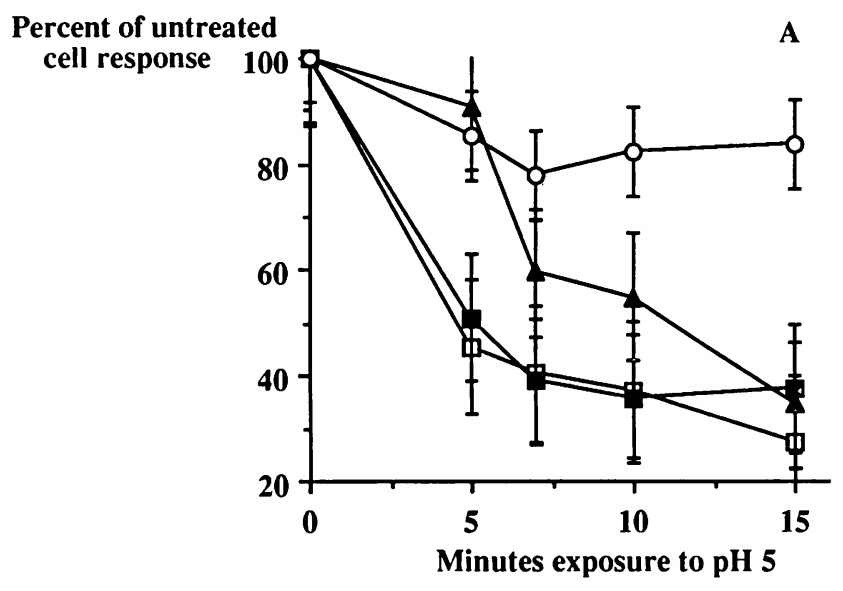

MAb added back

B to $\mathrm{pH} 5$ exposed

$\mathrm{T}$ cells

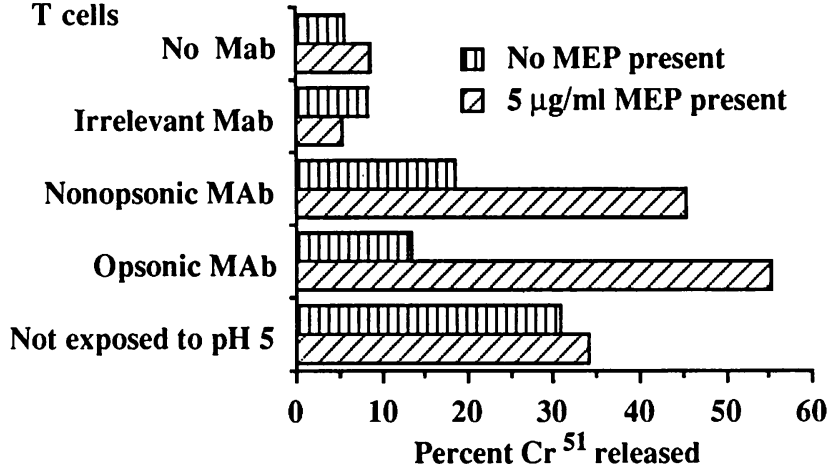

Figure 6. Immune complexes mediate cytotoxic activity. $(A)$ Immune $\mathrm{T}$ cells from mice immunized $8 \mathrm{~d}$ previously with $50 \mu \mathrm{g}$ of MEP antigen were exposed to $\mathrm{pH} 5$ in order to release surface-bound immune complexes. After exposure to $\mathrm{pH} 5$ for the indicated period, cells were quickly diluted into neutral-pH media, washed, counted for viability, and adjusted to an E:T target ratio of 20:1. Target cells were of the $8 / 5) 31$ hybridoma line. To cultures of the treated effector and target cells were added normal mouse serum only $(\square)$, normal mouse serum plus $5 \mu \mathrm{g}$ of MEP antigen $/ \mathrm{ml}(\Delta)$, MEP-immune mouse serum only (匹), or MEP-immune mouse serum plus $5 \mu \mathrm{g}$ of MEP antigen $/ \mathrm{ml}$ (O).${ }^{51} \mathrm{Cr}$ release by these treated cells was compared with that by immune $\mathrm{T}$ cells not exposed to $\mathrm{pH} 5$. Points indicate the mean of triplicate determinations and error bars the standard error. The net percent release of ${ }^{51} \mathrm{Cr}$ from labeled hybridomas incubated with untreated immune $\mathrm{T}$ cells was $38 \%$. $(B)$ Restoration of cytotoxic activity by monoclonal antibody $(M A b)$ to immune T cells exposed to $\mathrm{pH} 5.0$ for $15 \mathrm{~min}$. Acid-exposed $\mathrm{T}$ cells were sensitized with either opsonic MAb 8)5/31, nonopsonic MAb M)K/16, the irrelevant MAb 3D9 or no MAb and added to labeled 8/5) 31 hybridoma cells in the presence or absence of MEP as indicated in the legend. Bars represent means of duplicate cultures. 

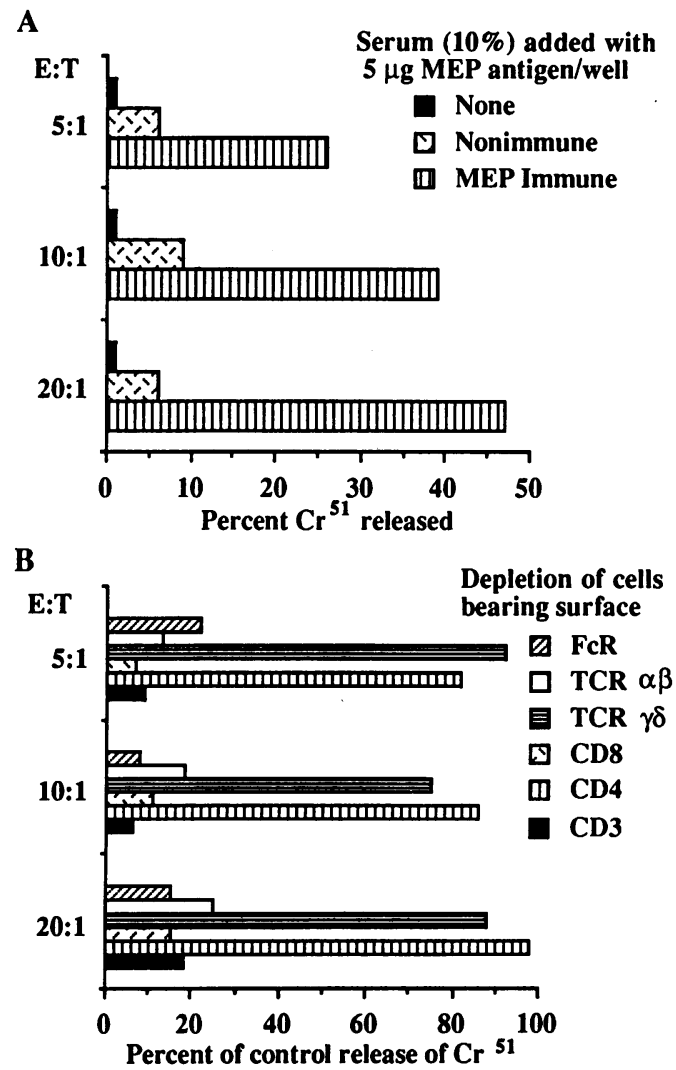

Figure 7. Cytotoxic activity of Con A-activated T cells from normal mice against hybridoma target 8/5)31. Bars indicate means of triplicate determinations. $(A)$ Normal murine $T$ cells were incubated for $48 \mathrm{~h}$ in the presence of $2.5 \mu \mathrm{g}$ of Con $\mathrm{A} / \mathrm{ml}$, harvested, washed, assessed for viability, added to labeled hybridoma target at the indicated $\mathrm{E}: \mathrm{T}$ ratio, and incubated for $18 \mathrm{~h}$. Added to each well was $5 \mu \mathrm{g}$ of MEP antigen along with no serum, normal mouse serum, or MEPimmune mouse serum. In the absence of added MEP antigen, no cytotoxic activity was observed (not shown). ( $B$ ) Depletion of Con A-activated $T$ cells with antibody specific to the indicated $T$ cell antigen. After depletion, $T$ cell viability was determined and the cells were incubated at the indicated E:T ratio with hybridoma 8/5)31 as the target in the presence of MEP-immune serum and $5 \mu \mathrm{g}$ of MEP antigen per well. The net percent release of ${ }^{51} \mathrm{Cr}$ from hybridomas in the presence of Con A-activated $\mathrm{T}$ cells treated with normal mouse serum was $52 \%$.

To characterize the cell surface markers on the Con A-activated $T$ cells, we performed depletion experiments using antibodies specific to $\mathrm{T}$ cell markers identical to those described in Fig. 2. Like immune CTL, most of the Con A-activated T cells expressed the CD3, CD8, and $\alpha \beta$ TCR antigens (Fig. $7 B$ ). In addition, both Con A-activated cells (Fig. $7 \mathrm{~B}$ ) and immune $\mathrm{T}$ cells exposed to $\mathrm{pH} 5$ for $15 \mathrm{~min}$ (not shown) could be depleted from reaction mixtures by monoclonal antibody $2.4 \mathrm{G} 2$, which is specific to the murine $\mathrm{FcR}_{\gamma}(22)$. These experiments indicated that $T$ cells that kill the hybridoma cells secreting opsonic antibody to $P$. aeruginosa MEP express the CD3, CD8, $\alpha \beta$ TCR, and FcR $\gamma$ surface markers.

Role of nonopsonic antibodies to MEP and immune complexes found in the sera of $C F$ patients in cytotoxicity. We next determined if the nonopsonic antibodies to MEP present in CF patient's sera before the onset of colonization $(9,18)$, could provide the antibody component of the immune complex needed to mediate $T$ cell killing of 8/5)31 cells if exogenous MEP antigen was provided. In addition, we tested whether antibodies and/or immune complexes were present in the sera of CF patients colonized with $P$. aeruginosa that could sensitize Con A-activated human peripheral blood $\mathrm{T}$ cells and mediate killing of the 8/5)31 hybridoma. Con A-activated peripheral blood $\mathrm{T}$ cells from volunteer blood donors were incubated with serum samples from individual CF patients lacking $P$. aeruginosa colonization (eight male, five female, mean age $11.8 \pm 10$ yr, range 4-41 yr) or with serum samples from CF patients colonized for $\geq 2 \mathrm{yr}$ with mucoid $P$. aeruginosa (nine male, four female, mean age 18.5 $\pm 12.4 \mathrm{yr}$, range 3-39 yr). Killing of the 8/5) 31 hybridoma and control $\mathrm{M} / \mathrm{K}) 16$ and $\mathrm{P} 3 \mathrm{X}$ cell lines was evaluated in the presence or absence of added MEP antigen. Results are shown in Fig. 8.

Sera from noncolonized CF patients, in the absence of added MEP antigen, did not mediate killing of the 8/5)31 hybridoma any better than they mediated killing of the control hybridoma and myeloma cell lines (Mann-Whitney U-test $P$ values 0.27 and 0.92 , respectively). However, in the presence of $5 \mu \mathrm{g}$ MEP per well, there was significantly greater killing of the 8/5) 31 targets than in its absence (paired $t$ value $-2.38, P$ $=0.035$, two-tailed). There was no enhanced killing of the control target cell lines upon addition of MEP antigen to the noncolonized patient's sera $(P \geq 0.4)$. In the presence of added MEP, there was significantly more killing of the 8/5)31 cells compared with the $\mathrm{M} / \mathrm{K}$ ) 16 or $\mathrm{P} 3 \mathrm{X}$ lines (Mann-Whitney $\mathrm{U}$ test $P$ values 0.04 and 0.05 , respectively). This finding shows that the antibody component needed to mediate killing of cells producing opsonic antibodies to MEP is present in younger $\mathrm{CF}$ patients prior to $P$. aeruginosa colonization.

Sera from chronically colonized CF patients mediated the highest level of killing of hybridoma 8/5)31 in the absence of added MEP antigen, with no significant change in target cell lysis if MEP was added (Fig. 8, paired $t$ value $-0.02, P=0.99$, two-tailed). In both the presence and absence of added MEP antigen, the killing of $8 / 5) 31$ was significantly greater than killing of the control M/K) 16-E2 and P3X cell lines (MannWhitney $U$ test $P$ values $0.007-0.04)$. Lysis of the control target cells was not significantly $(P \geq 0.5)$ enhanced or inhibited by the addition of MEP antigen. These findings indicate that colonized CF patients have circulating immune complexes capable of arming $T$ cells to kill hybridoma cells producing opsonic antibody to MEP.

The data in Fig. 8 were analyzed to compare the killing of the three cellular targets when sera from colonized or noncolonized CF patients were employed. The killing of the control cell lines $\mathrm{M} / \mathrm{K}$ ) 16-E2 or P3X was not different when the assays were run with sera from colonized or noncolonized patients in the presence or absence of added MEP antigen ( $P$ values 0.40 1, Mann-Whitney U test). However, in the absence of added MEP antigen, killing of the 8/5)31 hybridoma was greater by sera from colonized patients compared with killing by sera from noncolonized patients $(P=0.005$, Mann-Whitney $U$ test). Creating immune complexes in vitro by adding MEP antigen to sera from noncolonized CF patients increased killing of hybridoma 8/5)31 to a level where the difference between these sera and sera from colonized CF patients was negated $(P=0.25$, Mann-Whitney $U$ test $)$. Thus addition of MEP antigen to sera from noncolonized patients resulted in formation of immune complexes that were comparable to those already present in the sera of colonized patients that 


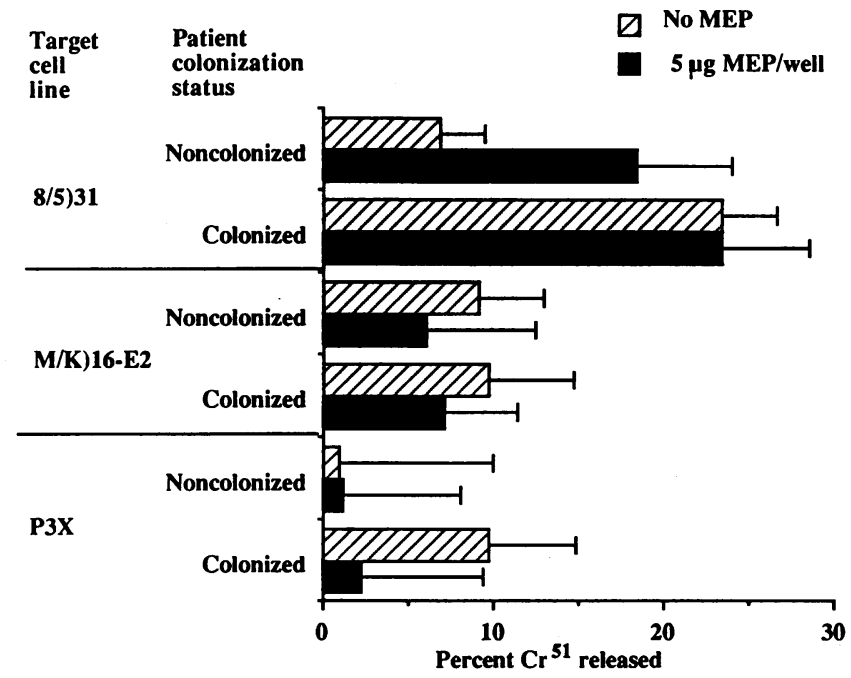

Figure 8. Cytotoxic activity of Con A-activated human peripheralblood T cells. Labeled hybridoma targets were incubated with Con A-activated non-CF human $T$ cells and $1 \%$ concentrations of antibody from CF patients either colonized or noncolonized by $P$. aeruginosa in the presence or absence of $5 \mu \mathrm{g}$ MEP per well. T cells were activated for $48 \mathrm{~h}$ with $2.5 \mu \mathrm{g}$ Con $\mathrm{A} / \mathrm{ml}$, washed, assessed for viability, and then added at an E:T ratio of 25:1 to the indicated hybridoma or myeloma target along with the indicated antibody preparation and MEP antigen. Percent release of ${ }^{51} \mathrm{Cr}$ was determined after $16 \mathrm{~h}$. Bars represent the mean for the populations, with individual samples tested in duplicate. Error bars represent the standard error.

could arm T cells for cytotoxic killing of B cells producing opsonic antibody to MEP.

\section{Discussion}

The mechanism by which $T$ cells interact with $B$ cells is usually based on MHC-restricted interactions wherein protein antigens can be processed and presented by B cells to T cells (2325 ). Our system differs in that a polysaccharide antigen-specific hybridoma cell line is killed by a typicai $\mathrm{CD} 8^{+}$, cytotoxic $\mathrm{T}$ cell expressing $\alpha \beta$ TCR and FcR $\gamma$. The requirement for an immune complex and the presence of FcR on these cells is consistent with the lack of MHC restriction we observed when $T$ cells from different strains of mice were tested for cytotoxic activity, and is also consistent with the ability of Con A-activated human $\mathrm{T}$ cells to kill this murine hybridoma in the presence of antibody and antigen. The mechanism described here for killing an antibody secreting $B$ cell by a $T$ cell may be generally applicable to the regulation of the immune response to other polysaccharides, particularly in the presence of high levels of antigen. This concept is supported by studies showing that serum and immune complexes containing polysaccharides from tolerant mice are capable of transferring nonresponsiveness to naive mice $(26,27)$. Also, $\mathrm{FcR}^{+} \mathrm{T}$ cells have been implicated as regulators of antibody production and of the proliferation of both myeloma and hybridoma cells $(28,29)$. T cells are known to regulate the immune response to polysaccharides (30-35), particularly in humans, where the T cell-regulated IgA and IgG isotypes predominate in the response to polysaccharide antigens $(18,36)$.

A central question from this study is why the hybridomas secreting opsonic antibody to MEP are susceptible to lysis, whereas those secreting nonopsonic antibodies resist cytotoxic $\mathrm{T}$ cell lysis. We observed that $\mathrm{T}$ cells mediating cytotoxic activity can be armed with either opsonic or nonopsonic antibody bound to their FcR. This $T$ cell bound antibody binds MEP antigen, which in turn binds to membrane bound Ig on the surface of the target hybridoma cell. In that the biologic activity of the antibody bound to the FcR on the T cell is irrelevant to the expression of cytotoxicity, any differences in susceptibility to lysis of hybridomas targeted by the $T$ cells must depend on the interactions of the membrane bound antibody on the hybridoma and the MEP antigen bound to the T cell. An important difference we have defined between the binding of opsonic and nonopsonic antibody to MEP is the lower density on the MEP antigen of epitopes that bind opsonic versus nonopsonic antibodies (11). This difference could potentially explain the susceptibility to lysis of the hybridomas secreting opsonic antibody, and the resistance of the hybridomas secreting nonopsonic antibodies to the same antigen. Antigen-mediated crosslinking of surface Ig on the hybridomas producing opsonic antibody is likely markedly less than on the hybridomas producing nonopsonic antibody. The degree of cross-linking of membrane Ig and the affinity of the antigen-antibody interaction have been shown to affect the B cell's activation state (37). A higher level of cross-linking of surface Ig on the cell producing the nonopsonic antibody may achieve a greater state of activation that renders the cell resistant to lysis, perhaps owing to increased production of interleukin 6 , a cytokine that protects hybridoma and leukemic cells against apoptosis associated with cell death $(38,39)$. We cannot completely exclude a more trivial explanation for these results, this being that some special property of the two hybridomas secreting opsonic antibody, such as surface Ig density, may render them susceptible to $\mathrm{T}$ cell lysis. We believe this highly unlikely, since these results are consistent with the observation that in the presence of preexisting nonopsonic antibody to MEP, opsonic antibody does not routinely develop $(9,12)$. In addition, when low doses of MEP are given to nonimmune mice, opsonic antibody responses are routinely made, indicating that these antibodies can be elicited under conditions where immune complex formation is limited. As shown in Fig. 1 , mice given a $1 \mu \mathrm{g}$ dose of MEP do not develop cytotoxic $T$ cells, and these mice have serum opsonic antibody (12).

Our data do not support a role for antibody isotype as contributing to the difference in opsonic and nonopsonic activity. As shown here and elsewhere $(11,12)$ antigen specific $\operatorname{IgG}_{2 b}$ murine monoclonal antibodies can have either biologic activity. They differ in their epitope specificity (11), and four to five times as many molecules of nonopsonic MAb bind to the bacterial surface as do opsonic MAbs (11). In addition, analysis of serum immune responses in mice and humans for antigen-specific isotype differences in sera with opsonic or nonopsonic activity failed to document any obvious difference, particularly in humans, where $\mathrm{IgM}, \mathrm{IgG}_{1}$, and $\operatorname{IgG}_{2}$ antibodies to MEP have been found in roughly equal amounts in sera with opsonic and nonopsonic activity (unpublished observation). However, for cytotoxic $\mathrm{T}$ cell activity described here it is likely that antibody isotype would be important, inasmuch as FcR usually bind a limited number of antibody isotypes usually with different affinities, depending on the isotype. Indeed the IgM MAb produced by hybridoma $\mathrm{M}$ ) K/ 16-C3 fails to sensitize Con A-activated $T$ cells for cytotoxic activity (unpublished observation), either due to an inability of FcR on cytotoxic cells to bind IgM, 
or the inability of T cells expressing receptors for IgM (40) to mediate cytotoxic activity.

We and others $(7,18)$ have shown that, before the onset of microbiologically documented $P$. aeruginosa infection, CF patients have detectable levels of serum antibody to MEP. Levels rise considerably once chronic infection is established $(7,18$, $41,42)$. Indeed, circulating nonopsonic antibodies to MEP are routinely found in all non-CF humans examined $(9,18)$, as well as in infants $>6$ mo of age (unpublished observation). Thus it seems possible that upon infection with $P$. aeruginosa, elaboration of the MEP antigen would result in the formation of immune complexes between antigen and preexisting nonopsonic antibodies, and these could mediate cytotoxic $T$ cell killing of B cells that otherwise would secrete opsonic antibodies that could participate in bacterial killing and elimination. We believe the absence of these opsonic antibodies may be important in establishing chronic infections by mucoid $P$. aeruginosa in CF patients. This idea is consistent with our finding that colonized CF patients uniformly lack opsonic antibodies to MEP (9). Pedersen et al. (43) have shown that CF patients harboring strains of $P$. aeruginosa that are phenotypically nonmucoid in vitro nonetheless respond to infection with antibody to MEP. This in vivo finding followed our initial observation (44) and that of Anastassiou et al. (45) that nonmucoid strains of $P$. aeruginosa elaborate small quantities of MEP antigen in vitro. Thus the nonmucoid strains that are thought to initially colonize $\mathrm{CF}$ patients may elaborate sufficient quantities of MEP in vivo that can complex with preexisting nonopsonic antibody and arm activated T cells to kill B cells that otherwise would produce protective, opsonic antibodies to this antigen. Under these conditions the mucoid form of $P$. aeruginos $a$ can emerge and escape elimination by host defenses.

We observed that CF patients colonized with mucoid $P$. aeruginosa had high levels of circulating immune complexes that could sensitize Con A-activated human $\mathrm{T}$ cells for cytotoxic killing of murine hybridomas. However, we did not determine if CF patients have comparable cytotoxic $\mathrm{T}$ cells. It is likely that such $\mathrm{T}$ cells are present and active at a time and in a fashion that would allow chronic $P$. aeruginosa infection to be established. The likelihood that CF patients have $\mathrm{CD}^{+}$activated $\mathrm{T}$ cells is supported by the findings of Smith et al. (46), who showed that lymphocytes from CF patients with chronic $P$. aeruginosa infection had greater levels of antibody-dependent cellular cytotoxicity directed against antibody-coated Chang cells compared with lymphocytes from noncolonized patients. This indicates that infected patients have activated lymphocytes that can kill eukaryotic target cells.

In conclusion, using surface immune complexes as the recognition unit, T cells from mice immunized with $50 \mu \mathrm{g}$ of MEP from $P$. aeruginosa can kill hybridoma cells secreting opsonic antibody to this antigen. A similar kind of immune complex is found in the blood of CF patients colonized with $P$. aeruginosa, and this complex can arm Con A-activated human $\mathrm{T}$ cells to kill the same target hybridomas. Immune complexes mediating cytotoxic activity were absent among younger CF patients lacking $P$. aeruginosa colonization, but the antibody component of these immune complexes was present, indicating the potential for rapid development of cytotoxic cells against B cells once antigen is introduced at high enough levels by the onset of colonization and/or infection. We believe this to be a potential mechanism that allows mucoid $P$. aeruginosa to escape the host defenses of CF patients. MEP-specific opsonic antibody has been elicited in the presence of preexisting nonopsonic antibody in mice immunized with very large $\left(K_{\mathrm{d}}>0.1\right.$, approximate molecular size $>2,000 \mathrm{kD}$ ) polymers of MEP (12); these larger polymers also fail to provoke murine cytotoxic $\mathrm{T}$ cells following immunization with $50-\mu \mathrm{g}$ doses ( unpublished observation). If the large polymers routinely elicit opsonic antibody in humans, provision of these opsonins by active immunization before infection and by passive immunization after infection may be a viable strategy for influencing the course of chronic $P$. aeruginosa infection in CF patients.

\section{Acknowledgments}

We would like to thank Drs. Dennis Kasper, David Schwartz, and Joanna Goldberg for critical review of the manuscript and the staff at Children's Hospital, Boston for helping to obtain the serum samples.

This work was carried out with support from the National Institutes of Health (grant numbers AI-22806 and AI-22456).

\section{References}

1. Barnaba, V., A. Franco, A. Alberti, R. Benvenuto, and F. Balsano. 1990. Selective killing of hepatitis B envelope antigen-specific B cells by class I-restricted, exogenous antigen-specific T lymphocytes. Nature (Lond.). 345:258260.

2. Russell, N. J., and P. Gacesa. 1988. Chemistry and biology of the alginate of mucoid strains of Pseudomonas aeruginosa in cystic fibrosis. Mol. Aspects Med. 10:1-91.

3. di Sant'Agnese, P. A., and P. B. Davis. 1979. Cystic fibrosis in adults: 75 cases and a review of 232 cases in the literature. Am. J. Med. 66:121-132.

4. Hoiby, N., and N. H. Axelsen. 1973. Identification and quantitation of precipitins against Pseudomonas aeruginosa in patients with cystic fibrosis by means of crossed immunoelectrophoresis with intermediate gel. Acta. Pathol. Microbiol. Scand. Sect. B Microbiol. 81:298-308.

5. Hoiby, N., V. Andersen, and G. Bendixen. 1975. Pseudomonas aeruginosa infection in cystic fibrosis. Acta Pathol. Microbiol. Scand. Sect. C Immunol. 83:459-468.

6. Fomsgaard, A., N. Hoiby, G. H. Shand, R. S. Conrad, and C. Galanos. 1988. Longitudinal study of antibody response to lipopolysaccharide during chronic Pséudomonas aeruginosa lung infection in cystic fibrosis. Infect. Immun. 56:2270-2278.

7. Pedersen, S. S., F. Espersen, N. Hoiby, and T. Jensen. 1990. Immunoglobulin-A and immunoglobulin-G antibody responses to alginates from Pseudomonas aeruginosa in patients with cystic fibrosis. J. Clin. Microbiol. 28:747-755.

8. Shand, G. H., S. S. Pedersen, M. R. Brown, and N. Hoiby. 1991. Serum antibodies to Pseudomonas aeruginosa outer-membrane proteins and iron-regulated membrane proteins at different stages of chronic cystic fibrosis lung infection. J. Med. Microbiol. 34:203-212.

9. Pier, G. B., J. M. Saunders, P. Ames, M. S. Edwards, H. Auerbach, J. Goldfarb, D. P. Speert, and S. Hurwitch. 1987. Opsonophagocytic killing antibody to Pseudomonas aeruginosa mucoid exopolysaccharide in older, non-colonized cystic fibrosis patients. $N$. Engl. J. Med. 317:793-798.

10. Pier, G. B., G. J. Small, and H. B. Warren. 1990. Protection against mucoid Pseudomonas aeruginosa in rodent models of endobronchial infection. Science (Wash. DC). 249:537-540.

11. Pier, G. B., M. Grout, and D. DesJardins. 1991. Complement deposition by antibodies to Pseudomonas aeruginosa mucoid exopolysaccharide (MEP) and by non-MEP specific opsonins. J. Immunol. 147:1869-1876.

12. Garner, C. V., D. DesJardins, and G. B. Pier. 1990. Immunogenic properties of Pseudomonas aeruginosa mucoid exopolysaccharide. Infect. Immun. 58:1835-1842.

13. Shinohara, N., Y. Y. Huang, and A. Muroyama. 1991. Specific suppression of antibody responses by soluble protein-specific, class-II restricted cytolytic T lymphocyte clones. Eur. J. Immunol. 21:23-27.

14. Shinohara, N., M. Watanabe, D. H. Sachs, and N. Hozumi. 1988. Killing of antigen-reactive $\mathrm{B}$ cells by class II-restricted, soluble antigen-specific CD8+ cytolytic T lymphocytes. Nature (Lond.). 334:481-484.

15. Pier, G. B., and M. Pollack. 1989. Isolation, structure, and immunogenicity of Pseudomonas aeruginosa immunotype 4 high-molecular-weight polysaccharide. Infect. Immun. 57:426-431.

16. Ames, P., D. DesJardins, and G. B. Pier. 1985. Opsonophagocytic killing activity of rabbit antibody to Pseudomonas aeruginosa mucoid exopolysaccharide. Infect. Immun. 49:281-285. 
17. Wysocki, L. J., and V. L. Sato. 1978. "Panning" for lymphocytes: a method for cell selection. Proc. Natl. Acad. Sci. USA. 75:2844-2848.

18. Pier, G. B., W. J. Matthews, and D. D. Eardley. 1983. Immunochemical characterization of the mucoid exopolysaccharide of Pseudomonas aeruginosa. J. Infect. Dis. 147:494-503.

19. Kumagai, K. T., T. Abo, T. Sekozawa, and M. Sasaki. 1975. Studies on surface immunoglobulins on human $B$ lymphocytes. I. Dissociation of cell bound immunoglobulins with acid $\mathrm{pH}$ or at $37^{\circ} \mathrm{C}$. J. Immunol. 115:982.

20. Markham, R. B., G. B. Pier, and J. R. Schreiber. 1991. The role of cytophilic IgG3 antibody in T-cell-mediated resistance to infection with the extracellular bacterium Pseudomonas aeruginosa. J. Immunol. 146:316-320.

21. Gillis, S., and K. A. Smith. 1977. Long term culture of tumor-specific cytotoxic T cells. Nature (Lond.). 268:154-156.

22. Unkeless, J. C. 1979. Characterization of a monoclonal antibody directed against mouse lymphocyte and macrophage Fc receptors. J. Exp. Med. 150:580592.

23. Chesnut, R. W., and H. M. Grey. 1986. Antigen presentation by B cells and its significance in T-B interactions. Adv. Immunol. 39:51-94.

24. Abbas, A. K. 1988. A reassessment of the mechanisms of antigen-specific T cell-dependent B cell activation. Immunol. Today. 45:1-5.

25. Noelle, R. J., and E. C. Snow. 1990. Cognate interactions between helper $\mathrm{T}$ cells and B cells. Immunol. Today. 11:361-368.

26. Caulfield, M. J., and D. Shaffer. 1987. Immunoregulation by antigen/antibody complexes. I. Specific immunosuppression induced in vivo with immune complexes formed in antibody excess. J. Immunol. 138:3680-3683.

27. Brown, P. B., H. Kohler, and D. A. Rowley. 1975. Specific suppression of the antibody response in vitro by serum from paralyzed mice. J. Immunol. 115:419-424.

28. Brunati, S., J. Moncuit, W. H. Friedman, and J. L. Teillaud. 1990. Regulation of IgG production by suppressor Fc-Gamma-RII+ T-hybridomas. Eur. J Immunol. 20:55-61.

29. Hoover, R. G., H. M. Gebel, B. K. Dieckgraefe, S. Hickman, N. F. Reebe N. Hirayam, Z. Ovary, and R. G. Lynch. 1981. Occurrence and potential significance of increased numbers of $\mathrm{T}$ cells with $\mathrm{Fc}$ receptors in myeloma. Immunol. Rev. 56:115-139.

30. Taylor, C. E., M. B. Fauntleroy, P. W. Stashak, and P. J. Baker. 1991. Antigen-specific suppressor T-cells respond to recombinant interleukin-2 and other lymphokines. Infect. Immun. 59:575-579.

31. Baker, P. J. 1990. Regulation of magnitude of antibody response to bacterial polysaccharide antigens by thymus-derived lymphocytes. Infect. Immun. 58:3465-3468

32. Markham, R. B., G. B. Pier, and W. G. Powderly. 1988. Suppressor T cells regulating the cell-mediated immune response to Pseudomonas aeruginosa can be generated by immunization with anti-bacterial T cells. J. Immunol. 141:39753979.
33. Muller, E., and M. Apicella. 1988. T-cell modulation of the murine antibody response to Neiserria meningitidis group A capsular polysaccharide. Infect. Immun. 56:259-266.

34. Braley-Mullen, H. 1990. Distinct populations of antigen-presenting cells are required for activation of suppressor and contrasuppressor T cells by type III pneumococcal polysaccharide. Cell. Immunol. 128:528-541.

35. Taylor, C. E., and R. Bright. 1989. T-cell modulation of the antibody response to bacterial polysaccharide antigens. Infect. Immun. 57:180-185.

36. Tarkowski, A., C. Lue, Z. Moldoveanu, H. Kiyono, J. R. McGhee, and J. Mestecky. 1990. Immunization of humans with polysaccharide vaccines induces systemic, predominantly polymeric IgA2-subclass antibody responses. $\mathrm{J} . \mathrm{Im}$ munol. 144:3770-3778.

37. Mongini, P. K. A., C. A. Blessinger, and J. P. Dalton. 1991. Affinity requirements for induction of sequential phases of human $B$ cell activation by membrane IgM-cross-linking ligands. J. Immunol. 146:1791-1800.

38. Yonish-Rouach, E., D. Resnitzky, J. Lotem, L. Sachs, A. Kimchi, and M. Oren. 1991. Wild-type p53 induces apoptosis of myeloid leukemic cells that is inhibited by interleukin-6. Nature (Lond.). 353:345-347.

39. Sabourin, L. A., and R. G. Hawley. 1990. Suppression of programmed death and $\mathrm{Gl}$ arrest in B-cell hybridomas by interleukin- 6 is not accompanied by altered expression of immediate early response genes. J. Cell. Physiol. 145:564574

40. Lynch, R. G., M. Sandor, T. J. Waldschmidt, A. Mathur, W. T. Schaiff, D. J. Berg, K. Snapp, A. Mueller, M. G. Robinson, N. Noben, et al. 1990. Lymphocyte $\mathrm{Fc}$ receptors-expression, regulation and function. Mol. Immunol 27:1167-1179.

41. Bryan, L. E., A. Kureishi, and H. R. Rabin. 1983. Detection of antibodies to $P$. aeruginosa alginate extracellular polysaccharide in animals and cystic fibrosis patients by enzyme-linked immunosorbent assay. J. Clin. Microbiol. 18:276282

42. Speert, D. P., D. Lawton, and L. Mutharia. 1984. Antibody to P. aeruginosa mucoid exopolysaccharide and to sodium alginate in cystic fibrosis sera. Pediatr. Res. 8:431-434.

43. Pedersen, S. S., A. Kharazmi, F. Espersen, and N. Hoiby. 1990. Pseudomonas aeruginosa alginate in cystic fibrosis sputum and the inflammatory response. Infect. Immun. 58:3363-3368.

44. Pier, G. B., D. DesJardins, T. Aguilar, M. Barnard, and D. P. Speert. 1986. Polysaccharide surface antigens expressed by non-mucoid isolates of Pseudomonas aeruginosa from cystic fibrosis patients. J. Clin. Microbiol. 24:189-196.

45. Anastassiou, E. D., A. S. Mintzas, C. Kounavis, and G. Dimitracopoulos. 1987. Alginate production by clinical nonmucoid Pseudomonas aeruginosa. J Clin. Microbiol. 25:656-659.

46. Smith, M. J., L. Morris, R. J. Stead, M. E. Hodson, and J. C. Batten. 1987. Lymphocyte subpopulations and function in cystic fibrosis. Eur. J. Respir. Dis. 70:300-308 